Rev. Int. Contam. Ambie. 35 (4) 815-829, 2019

DOI: 10.20937/RICA.2019.35.04.04

\title{
EVALUACIÓN DE LA TOXICIDAD DEL CLORPIRIFÓS EN ALEVINOS DE CACHAMA BLANCA (Piaractus brachypomus)
}

Toxicity assessement of chlorpyrifos in red-bellied pacu fingerlings (Piaractus brachypomus)

\author{
Gisella Karina HOLGUÍN CÉSPEDES, Laura Marcela MILLÁN OCAMPO, \\ Eily Jisseth MAHECHA MÉNDEZ, Ángel Enrique CÉSPEDES RUBIO e \\ Iang Schroniltgen RONDÓN BARRAGÁN*
}

Universidad del Tolima, Grupo de Investigación en Enfermedades Neurodegenerativas, Tolima, Ibagué, CP 730006299, Colombia

*Autor para correspondencia: isrondon@ut.edu.co

(Recibido: octubre 2017; aceptado: mayo 2019)

Palabras clave: letalidad, peces, plaguicidas, daño tisular, respuesta inmunitaria

\section{RESUMEN}

Los plaguicidas se han convertido en un importante problema ambiental debido a su utilización indiscriminada y al poco control en su uso, lo que termina afectando drásticamente a organismos que no son blanco de su acción, incluyendo especies acuáticas. Se determinó la toxicidad aguda y crónica del clorpirifós en alevinos de cachama blanca (Piaractus brachypomus) y se estableció el valor de la concentración letal media $\left(\mathrm{CL}_{50}\right)$ a $96 \mathrm{~h}$, la cual fue evaluada en 88 peces expuestos a concentraciones de clorpirifós de 0.015 a $1.5 \mu \mathrm{g} / \mathrm{L}$. El valor establecido para la $\mathrm{CL}_{50}$ fue de $0.11 \mu \mathrm{g} / \mathrm{L}(\mathrm{p}<0.05)$. El ensayo de toxicidad crónica a dosis subletales $\left(0.5,0.1\right.$ y $0.001 x$ de la $\left.C_{50}\right)$ se realizó en 60 animales por tratamiento más un grupo testigo, expuestos por 50 días, seguido por 50 días sin exposición, evaluándose tanto la actividad de explosión respiratoria como la capacidad bactericida del plasma en un desafío a Aeromonas hydrophila. Se encontraron niveles menores de explosión en el grupo expuesto a $0.0011 \mu \mathrm{g} / \mathrm{L}$ en los días 20 y 50 y un incremento en el grupo expuesto a $0.055 \mu \mathrm{g} / \mathrm{L}$ al día 90 ; además, la actividad bactericida del plasma mostró una disminución hasta el día 40 en los animales expuestos comparados con el grupo testigo. Adicionalmente, en un ensayo de exposición subcrónica sin recuperación a dosis subletal de clorpirifós $(0.011 \mu \mathrm{g} / \mathrm{L})$, se hallaron lesiones en branquias, hígado, riñón y encéfalo. Este estudio ha demostrado la alta sensibilidad de la especie al clorpirifós, por lo cual se postula a P. brachypomus como bioindicador de contaminación hídrica.

Keywords: lethality, fish, pesticides, tissue damage, immune response

\begin{abstract}
Pesticides have become an important environmental problem due to their indiscriminate and lack of control use, which ends up affecting drastically non-target organisms, including aquatic species. The acute and chronic toxicity of chlorpyrifos was determined in fingerlings of red-bellied pacu (Piaractus brachypomus), and it was established the value of the median lethal concentration $\left(\mathrm{LC}_{50}\right)$ at $96 \mathrm{~h}$, which was evaluated in 88 fish exposed to chlorpyrifos concentrations from 0.015 to $1.5 \mu \mathrm{g} / \mathrm{L}$. The value established
\end{abstract}


for $\mathrm{CL}_{50}$ was $0.11 \mu \mathrm{g} / \mathrm{L}(\mathrm{p}<0.05)$. The chronic toxicity test to sublethal doses $(0.5$, 0.1 and $0.001 x$ of the $\mathrm{LC}_{50}$ dose) was performed in 60 animals per treatment plus a witness group. Animals were exposed for 50 days, followed by 50 days without exposure, to evaluate both respiratory burst activity and plasma bactericidal activity in a challenge with Aeromonas hydrophila. Lower levels of respiratory burst were found in the exposed group to $0.0011 \mu \mathrm{g} / \mathrm{L}$ in 20 and 50 days, which increased in the exposed group to $0.055 \mu \mathrm{g} / \mathrm{L}$ at day 90 . In addition, the bactericidal activity of plasma showed a decrease until day 40 in exposed animals compared to the witness. Also, in a trial of subchronic exposure without recovery to sublethal doses of chlorpyrifos $(0.011 \mu \mathrm{g} / \mathrm{L})$, lesions were found in gills, liver, kidney and brain. This study has demonstrated the high sensitivity of this species to chlorpyrifos, postulating P. brachypomus as a bioindicator of water pollution.

\section{INTRODUCCIÓN}

El uso indiscriminado de plaguicidas en actividades agropecuarias a nivel mundial y especialmente en países en desarrollo, ha aumentado significativamente durante las últimas décadas (De et al. 2014, FAOSTAT 2015). Diversos estudios han descrito el impacto ambiental de la acumulación de estos compuestos en cuerpos de agua y sus efectos en poblaciones acuáticas (Naddy y Klaine 2001). El clorpirifós (O,O-dietil O-3,5,6-tricloro-2-piridinil fosforotioato) es un insecticida de amplio espectro perteneciente al grupo de los organofosforados (WHO 2004), del cual se ha comprobado que menos del $0.1 \%$ alcanza la plaga objetivo y el $99.9 \%$ restante llega a los diferentes componentes del ambiente (Pimentel 1995). Por ser un plaguicida hidrofóbico, su eliminación en eventos de lluvia es casi nula y su persistencia en sedimentos de sistemas hídricos se convierte en un problema (Kimbrough y Litke 1996) que compromete el bienestar de organismos acuáticos y es el causante de muertes masivas de los mismos (Schimmel et al. 1983).

El clorpirifós (CPF) también conocido como metrifonato, ha demostrado tener efectos tóxicos en mamíferos, peces, anfibios e invertebrados, afectando principalmente el sistema nervioso mediante la inhibición de la acetilcolinesterasa (AChE) (Kavitha y Venkateswara 2008). La sensibilidad a este compuesto varía con la especie; así, la $\mathrm{CL}_{50}$ a $96 \mathrm{~h}$ en insectos puede presentar rangos divergentes, dependiendo de la cepa y distribución geográfica de la especie (Bisset-Lazcano et al. 2009, García-Vidal et al. 2014, Páez-Jerez et al. 2015).

En peces, diversos estudios han demostrado la toxicidad del CPF en diferentes estadios de desarrollo (Jin et al. 2015). En tilapia del Nilo (Oreochromis niloticus) la $\mathrm{CL}_{50}$ a $96 \mathrm{~h}$ para juveniles fue de 98.67 $\mu \mathrm{g} / \mathrm{L}$ y para adultos de $154.01 \mu \mathrm{g} / \mathrm{L}$ (Oruç 2010), concentraciones cercanas a las descritas en el guppy (Poecilia reticulata) con una $\mathrm{CL}_{50}$ de $176 \mu \mathrm{g} / \mathrm{L}$ (Sharbidre et al. 2011). No obstante, en Pimephales promelas los valores de $\mathrm{CL}_{50}$ son mayores a $338 \mu \mathrm{g} / \mathrm{L}$ del mismo compuesto (Mehler et al. 2008). Además de sus efectos letales, diversos estudios han demostrado los efectos de la exposición subletal asociados con genotoxicidad, inmunotoxicidad y neurotoxicidad, entre otros (Ali et al. 2008, Xing et al. 2012a, Khalil et al. 2013).

La evaluación de los cambios en el comportamiento de animales expuestos, así como la evaluación histopatológica y bioquímica son herramientas de soporte en estudios de ecotoxicología (Drummond y Russom 1990, Cohn y MacPhail 1996), ya que permiten la identificación de problemas relacionados con neurotoxicidad, inmunotoxicidad y la afección de otros sistemas orgánicos.

El objetivo del presente estudio fue determinar la toxicidad expresada en $\mathrm{CL}_{50}$ a $96 \mathrm{~h}$, así como la toxicidad subletal y subcrónica del CPF en alevinos de cachama blanca (Piaractus brachypomus); adicionalmente, identificar las variaciones histopatológicas asociadas con la exposición subcrónica a una dosis subletal de CPF.

\section{MATERIALES Y MÉTODOS}

\section{Animales}

Se utilizaron 368 alevinos de $P$. brachypomus con un peso de $5 \pm 0.5 \mathrm{~g}, 88$ de ellos para la determinación de $\mathrm{CL}_{50}$ y 280 para la exposición subcrónica a dosis subletales. Todos los peces fueron sometidos a un periodo previo de aclimatación (15 días) y se mantuvieron en acuarios de vidrio a una densidad menor o igual a $1 \mathrm{~g} / \mathrm{L}$ (OECD 1992), con aireación constante sin filtro y condiciones de $\mathrm{pH}$, temperatura y confort adaptados para esta especie. 
Como mecanismo de prevención, se trataron con cloruro de sodio $(\mathrm{NaCl})$ al $0.2 \%$ a fin de eliminar ectoparásitos según lo descrito por Floyd (1999). El suministro de alimento fue controlado ( $2 \%$ de su peso corporal) y administrado dos veces al día con un producto comercial (Mojarra $32 \%$, ® SOLLA). Al inicio del experimento los alevinos se encontraban clínicamente sanos y fueron evaluados siguiendo los lineamientos descritos en Floyd (1999) y Campbell (2005), los cuales califican el patrón de nado y sus alteraciones (e.g., nado en espiral, nado en círculos, nado explosivo [movimientos de nado con desplazamiento súbito y rápido]), el comportamiento de cardumen, el consumo de alimento, la distribución en la columna de agua, ausencia de boqueo, reflejo de huida, presencia de lesiones cutáneas, respuesta a la presión del pedúnculo caudal, entre otras.

Este proyecto fue aprobado por el Comité Local de Ética siguiendo la normatividad (Ley 84 de 1989 y Resolución 8430 de 1993) para el uso de animales vivos en experimentación, así como los criterios internacionales sobre experimentos con peces (OECD 1992). Todos los experimentos, se realizaron en los laboratorios de Toxicología y Microbiología de la Universidad de Tolima.

\section{Sustancias experimentales}

Se utilizó clorpirifós (0,0-dietil 0-[3.5.6-tricloro2-piridinil] fosforotioato; Dow AgroSciences, Colombia) al $48 \%$ y como solvente, acetona grado reactivo (Merck, Alemania) para obtener una solución madre de $4.8 \mathrm{mg} / \mathrm{mL} \mathrm{y}$, a partir de ésta, la solución de trabajo a una concentración de $48 \mu \mathrm{g} / \mathrm{mL}$.

\section{Ensayo de concentración letal media ( $\left.\mathrm{CL}_{50}\right)$}

Para el ensayo de la $\mathrm{CL}_{50}$ del $\mathrm{CPF}$, se siguieron los lineamientos de ensayo de toxicidad aguda descrito por la OECD (1992). Se emplearon siete grupos de tratamiento y un grupo testigo, cada uno con 11 animales. Los peces fueron expuestos durante $96 \mathrm{~h}$ a concentraciones de 0.015, 0.02, 0.07, 0.09, 0.13, 0.15 y $1.5 \mu \mathrm{g} / \mathrm{L}$ de CPF obtenidas a través de ensayos preliminares; para éstos se evaluaron concentraciones de $0.0076,0.076,0.76,7.6,90,120,160,300,600$, 1200 y $2500 \mu \mathrm{g} / \mathrm{L}$ de CPF en tiempos de exposición de $96 \mathrm{~h}$ que permitieron establecer el rango de la $\mathrm{CL}_{50}$ a evaluar. Los experimentos se realizaron mediante un sistema semiestático con recambio del $50 \%$ del agua cada $24 \mathrm{~h}$, adicionando la mitad de la concentración para mantener los valores iniciales. Las observaciones se realizaron cada $3 \mathrm{~h}$ y se registraron los cambios comportamentales (patrón de nado [e.g., eje de nado, movimiento en desplazamiento y estación], el comportamiento de cardumen, el reflejo de huida, la ubicación en los tercios de la columna de agua y la agresividad [e.g., movimiento rápido en dirección a los demás individuos experimentales con apertura de mandíbulas sugiriendo intención de morder]), así como la mortalidad en cada uno de los tratamientos.

\section{Exposición subcrónica sin recuperación a dosis subletal de CPF}

Se usaron un total de 40 alevinos de $P$. brachypomus, 20 expuestos a $0.011 \mu \mathrm{g} / \mathrm{L}$ de CPF (correspondientes a la décima parte de la $\mathrm{CL}_{50}$ $[0.11 \mu \mathrm{g} / \mathrm{L}]$ con base en los resultados previos) y 20 para el grupo testigo no expuesto, por un periodo de 25 días sin recuperación posterior. Finalizado el periodo experimental, los animales fueron anestesiados con Eugenol ${ }^{\circledR}(40 \mathrm{mg} / \mathrm{L})$ e inmediatamente sacrificados; se tomaron muestras de branquias, hígado, riñón y cerebro, siguiendo los protocolos de necropsia descritos por Yanong (2003). Los tejidos se fijaron en formalina amortiguada al $10 \%$ y procesados por la técnica de hematoxilina y eosina (Luna 1968). La evaluación histopatológica se realizó con un microscopio óptico (Olympus IX73P2F, EUA). Las imágenes digitales se capturaron con una cámara Olympus U-TV0.5XC-3 (Tokyo, Japón) y el programa Cellsens Standard 1.12 (2009-2014).

\section{Exposición crónica subletal del CPF}

Para los experimentos de subletalidad del CPF, se utilizaron las concentraciones correspondientes a la mitad (tratamiento $1=0.055 \mu \mathrm{g} / \mathrm{L}$ ), así como a la décima (tratamiento $2=0.011 \mu \mathrm{g} / \mathrm{L}$ ) y la milésima (tratamiento $3=0.0011 \mu \mathrm{g} / \mathrm{L}$ ) partes de $1 \mathrm{a} \mathrm{CL}_{50}$ determinada y un grupo testigo sin exposición al tóxico. La fase experimental tuvo una duración de 100 días en total con 50 días de exposición y 50 días de recuperación posexposición, a fin de evaluar la reversibilidad de los efectos inducidos. Se usaron 60 animales por tratamiento y los muestreos se realizaron cada 10 días tomando seis animales de cada tratamiento por etapa muestral.

\section{Explosión respiratoria}

La explosión respiratoria se midió siguiendo lo descrito por Mohanty y Sahoo (2010) mediante el método de reducción de azul de nitro-tetrazolio (NBT, por sus siglas en inglés) por espectrofotometría. Se combinaron $100 \mu \mathrm{L}$ de sangre tomados por venopunción con $100 \mu \mathrm{L}$ de solución de NBT (Sigma ${ }^{\circledR}$ Chemicals, Alemania) al $0.2 \%$, y se incubaron a $25^{\circ} \mathrm{C}$ por $30 \mathrm{~min}$. Seguidamente, se adicionaron 50 $\mu \mathrm{L}$ de la suspensión a un vial que contenía $1 \mathrm{~mL}$ de 
N,N-dimetilformamida y se centrifugó a $2000 \mathrm{rpm}$ por $5 \mathrm{~min}$. Posteriormente, en una placa multipozos (placa de 96 pozos) de fondo en U se depositó la solución para la lectura a $620 \mathrm{~nm}$ en un espectrofotómetro (ELx- 800-Biotek ${ }^{\circledR}$ Instruments, EUA). Los cambios en la densidad óptica se relacionaron con cambiosen la actividad oxidativa de los fagocitos.

\section{Ensayo de actividad bactericida del plasma frente a Aeromonas hydrophila}

Este enayo se realizó con base en el protocolo descrito por Rainger y Rowley (1993). A partir del plasma sanguíneo se realizaron mezclas por grupos de cada tratamiento por muestreo. De forma separada, se realizó una suspensión bacteriana de Aeromonas hydrophila en solución salina, ajustando dicha suspensión al tubo cero de la escala de McFarland con una densidad óptica de 0.075 a $560 \mathrm{~nm}$. Posteriormente, $100 \mu \mathrm{L}$ de plasma (de cada tratamiento) se mezclaron con 100 $\mu \mathrm{L}$ de dilución bacteriana y fueron incubados durante $1 \mathrm{~h}$ a $37^{\circ} \mathrm{C}$, seguido de centrifugación y tres lavados con agua destilada. El pellet final fue resuspendido en solución salina estéril $(200 \mu \mathrm{L})$ y sembrado de manera masiva en agar tripticasa soya (TSA, Oxoid, Alemania) e incubado a $37{ }^{\circ} \mathrm{C}$ por $24 \mathrm{~h}$. Finalmente, se realizó el conteo de unidades formadoras de colonias (UFC) en cada uno de los tratamientos para cada muestreo.

\section{Análisis estadístico}

Los datos obtenidos de la mortalidad acumulada en el ensayo de $\mathrm{CL}_{50}$ a $96 \mathrm{~h}$ para cada tratamiento fueron analizados mediante el programa Trimmed Spearman-Karber, TSK v. 4.1 (Hamilton et al. 1977). Se tomó en cuenta un nivel de confianza del $95 \%$. Los resultados fueron graficados mediante SPSS ${ }^{\circledR}$ v. 2.0 para Windows (IBM, EUA). Para el análisis del ensayo de subletalidad se utilizó un diseño experimental completamente aleatorizado de efecto fijo balanceado con la técnica de análisis de varianza (ANDEVA) y análisis multivariado de varianza (MANDEVA) donde las variables de respuesta fueron la densidad óptica (explosión respiratoria) y el número de colonias (capacidad bactericida del plasma). El modelo se ajustó de acuerdo con la siguiente ecuación: (Yij $=\mu+\tau I+\varepsilon j(I)$ ); donde $\mu$ es la media, $\tau I$ el efecto tratamiento, y $\varepsilon j(I)$ el error experimental.

Se realizó un análisis de Kruskall-Wallis seguido de la prueba de comparación múltiple de Dunn, previa validación de los supuestos del modelo. Los datos son presentados como el promedio \pm el error estándar de la media (ESM). Los resultados fueron analizados con el programa GraphPad Prism ${ }^{\circledR}$ v. 5.03 Windows (GraphPad Software 2007, California, EUA).

\section{RESULTADOS}

Durante la fase de aclimatación y la fase experimental no se observaron fluctuaciones significativas en los parámetros de calidad del agua. Asimismo, no se presentaron alteraciones clínicas de los sujetos experimentales.

\section{Toxicidad aguda (CL50)}

En el ensayo de toxicidad aguda no se observaron mortalidad ni cambios en el comportamiento de los animales pertenecientes al grupo testigo. $\mathrm{La} \mathrm{CL}_{50}$ a $96 \mathrm{~h}$ del clorpirifós para alevinos de $P$. brachypomus fue de $0.11 \mu \mathrm{g} / \mathrm{L}$ (IC $95 \%=0.10-0.12 ; \mathrm{p}<0.05$ ) (Fig. 1). Los cambios en el comportamiento de los peces expuestos en los primeros $30 \mathrm{~min}$ se caracterizaron por nado explosivo principalmente en las mayores concentraciones, así como incremento en la frecuencia opercular acompañado de la distribución de los peces en el tercio superior del acuario. Inicialmente se evidenció un nado rápido, acompañado de tremores continuos. Algunos individuos presentaron pérdida del eje de nado, nado errático o en espiral, que concluía en movimientos explosivos. Los peces inclinaban su cuerpo con la cabeza en dirección hacia abajo y se movían sin avanzar seguido de la disminución de movimientos de nado y frecuencia opercular hasta su cese total y muerte.

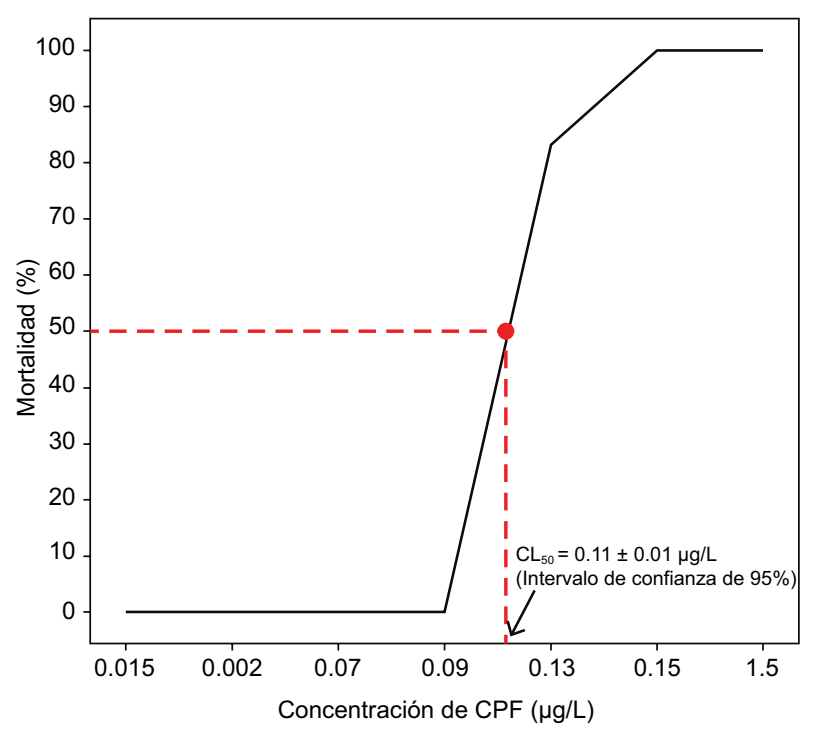

Fig. 1. Concentración letal $\left(\mathrm{CL}_{50}\right)$ de clorpirifós a 96 h en alevinos de Piaractus brachypomus. Análisis de regresión sigmoidea y $\mathrm{CL}_{50}$ de clorpirifós a $96 \mathrm{~h}$ en alevinos de cachama blanca 


\section{Exposición subcrónica sin recuperación a dosis subletal de CPF}

El análisis histopatológico de los individuos en el ensayo de exposición subcrónica reveló alteraciones en todos los tejidos analizados. A nivel branquial, los animales tratados con CPF $(0.011 \mu \mathrm{g} / \mathrm{L})$ evidenciaron hipertrofia del epitelio lamelar e hiperplasia del epitelio interlamelar moderada (Fig. 2b). En el hígado se halló una degeneración generalizada de los hepatocitos caracterizada por la presencia de vacuolas citoplasmáticas translúcidas que en la mayoría de las células no permitía distinguir el núcleo (Fig. 2d). En el tratamiento con $\mathrm{CPF}$, el riñón presentó depleción de leucocitos severa y degeneración hialina del epitelio tubular con acumulación de centros melanomacrófagos, pérdida de estructura y distribución de parénquima con algunas zonas de necrosis (Fig. 2f). En el encéfalo se evidenció degeneración hialina de los cuerpos neuronales, los cuales se tornaron eosinofilicos, además de hipertrofia celular (Fig. 2h).

\section{Exposición crónica subletal del CPF Explosión respiratoria}

Los animales del tratamiento $3(0.0011 \mu \mathrm{g} / \mathrm{L})$ evidenciaron valores menores de explosión respiratoria en los primeros 20 días $(0.02125 \pm 0.0061)$ y al día
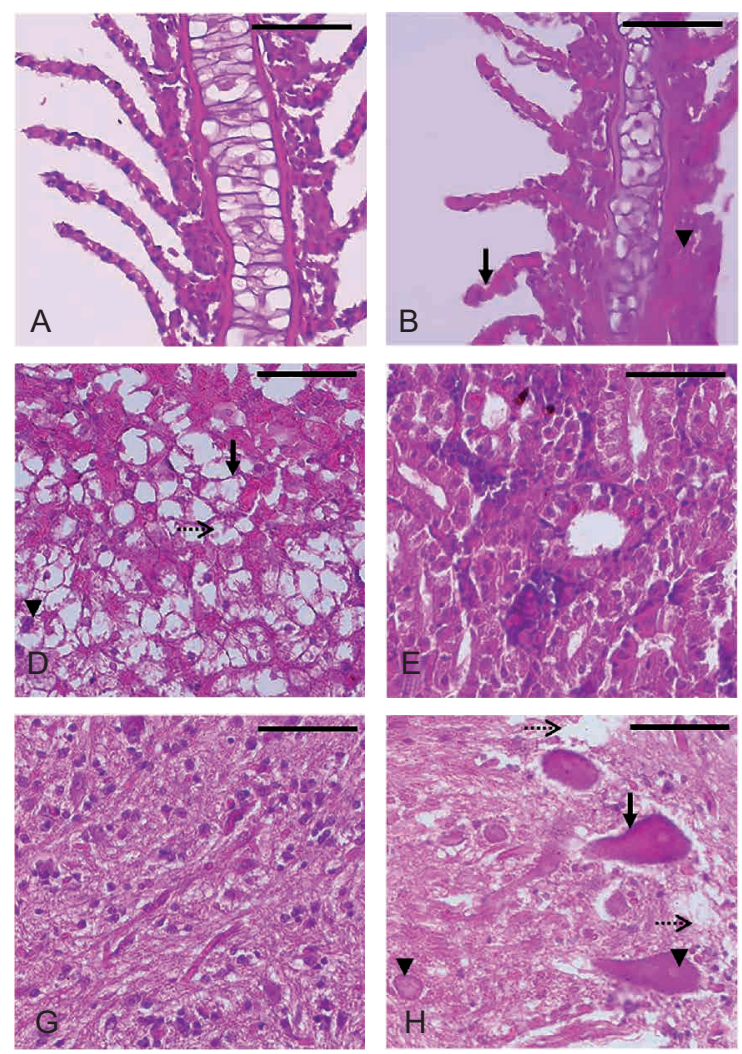
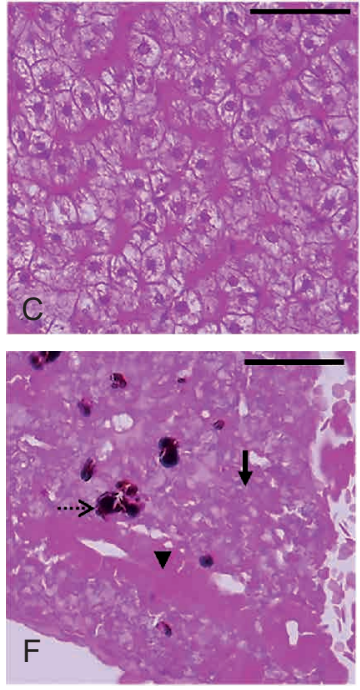

Fig. 2. Lesiones histopatológicas asociadas con exposición subcrónica a dosis subletal de clorpirifós (CPF) sin recuperación (hematoxilina y eosina, $40 \mathrm{X}$ ). Testigos y clorpirifós (CPF, $0.011 \mu \mathrm{g} / \mathrm{L}$ ). Branquias. (a) Testigo, espacios interlamelares limpios y células de morfología uniforme. (b) CPF, muestra, la hipertrofia del epitelio laminar (flecha) e hiperplasia interlamelar moderada (cabeza de flecha). Hígado. (c) Testigo, apariencia normal de hepatocitos. (d) CPF, amplia lipidosis, estructuras intracelulares-vacuolas (flecha), pleomorfismo nuclear (cabeza de flecha), fragmentación nuclear (flecha punteada). Riñón caudal. (e) Testigo, apariencia normal de estructuras tubulares. (f) $\mathrm{CPF}$, nefrosis vacuolar del epitelio tubular, pérdida de estructura y distribución de parénquima (flecha), reducción de espacio de Bowman (cabeza de flecha), melanomacrófagos (flecha punteada). Encéfalo. (g) Testigo, apariencia normal de neuronas con membrana y nucleo bien definidos. (h) CPF, degeneración neuronal con hipertrofia celular (flecha) y alteración nuclear (núcleo fantasma) (cabeza de flecha) degeneración celular y pérdida del neurópilo (flecha punteada). Barra de escala: $50 \mu \mathrm{m}$. 
50 de exposición $(0.03567 \pm 0.021)$, comparados con el grupo testigo (día $20=0.07683 \pm 0.023$; día 50 $=0.07217 \pm 0.01074)$. Los demás tratamientos no evidenciaron diferencias significativas durante todo el experimento, a excepción de un incremento en los niveles oxidativos en el tratamiento $1(0.055 \mu \mathrm{g} / \mathrm{L})$, al día 90 de experimentación $(0.1255 \pm 0.007)$, como se muestra en la figura 3.

\section{Actividad bactericida del plasma}

En la actividad bactericida del plasma se halló una disminución de la capacidad bactericida para los grupos expuestos respecto al grupo testigo. Dichas diferencias se evidenciaron en animales hasta el día 40 de exposición; posteriormente no se detectaron diferencias estadísticamente significativas respecto al grupo testigo (Fig. 4).
Muestreo 1
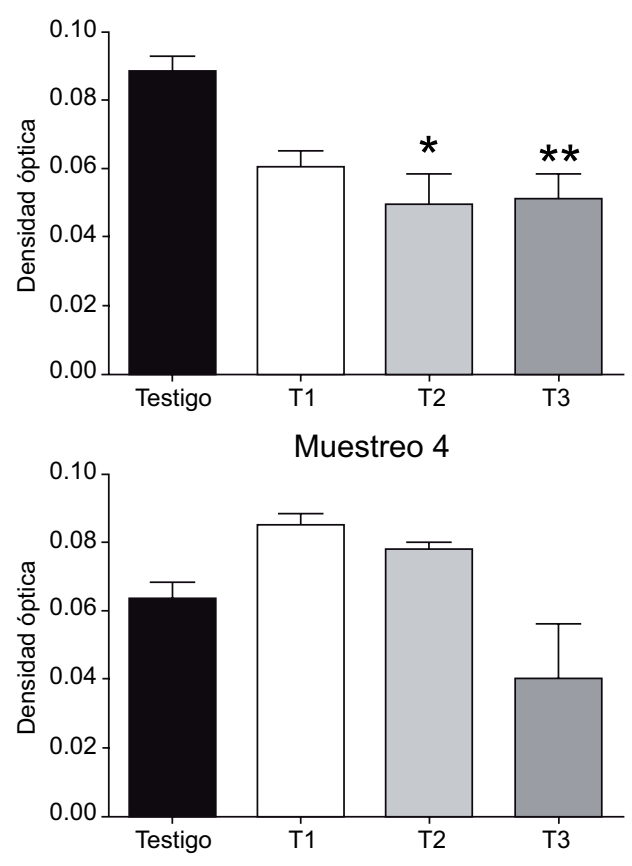

Muestreo 7
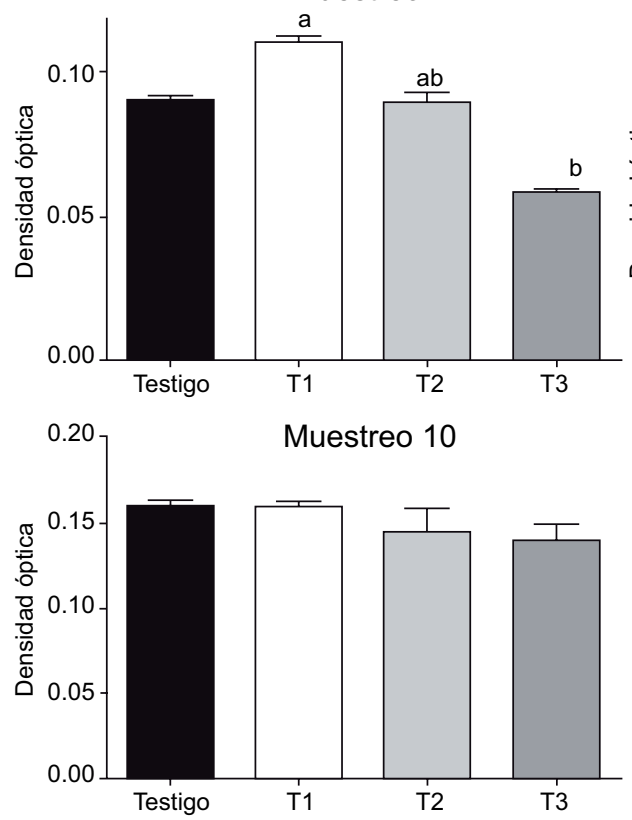

Muestreo 2
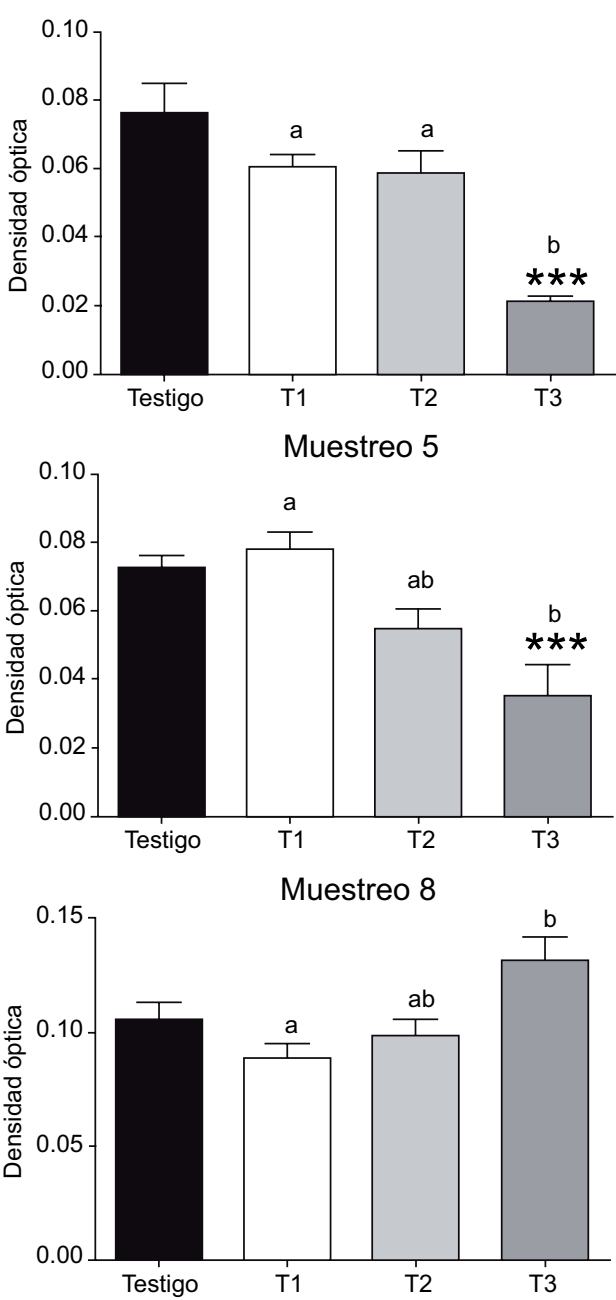
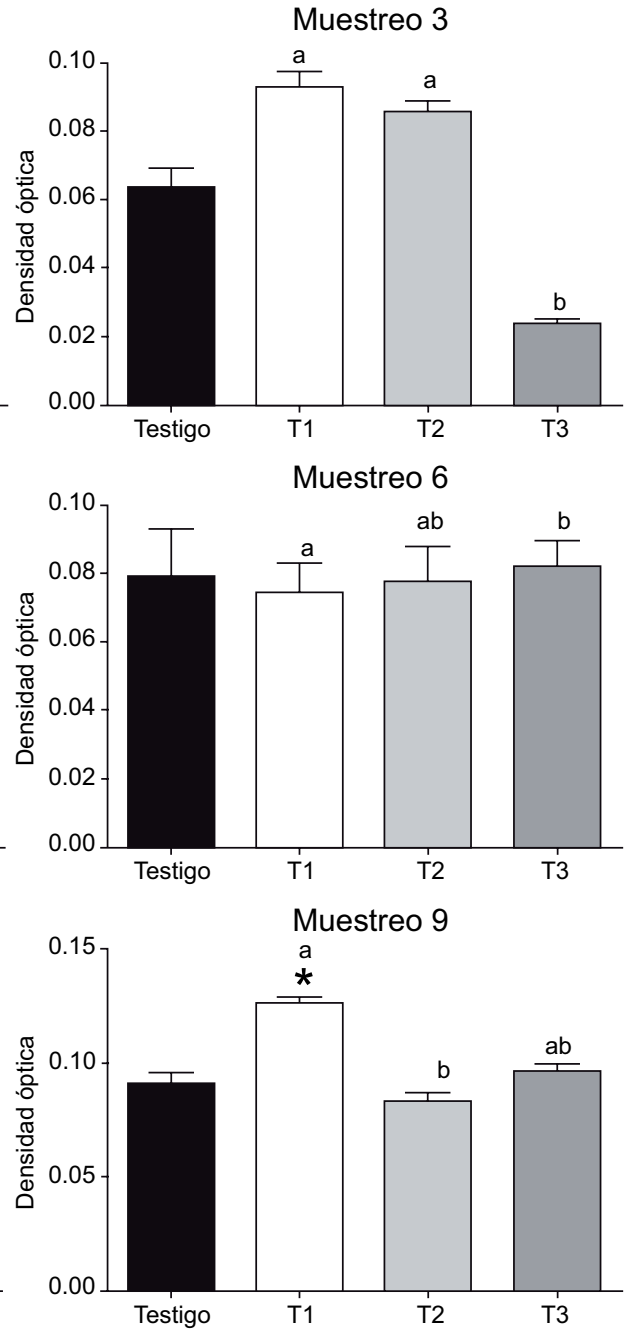

Fig. 3. Explosión respiratoria de juveniles de cachama blanca (Piaractus brachypomus) expuestos a clorpirifós por un periodo de 50 días seguido de un periodo de recuperación (no exposición) de 50 días. Letras diferentes describen diferencias significativas entre individuos expuestos a CPF. Los asteriscos describen diferencias significativas de los tratamientos $(\mathrm{T})$ expuestos vs. el grupo testigo: ${ }^{*} \mathrm{p}<0.05$, $* * \mathrm{p}<0.01, * * * \mathrm{p}<0.001$ 

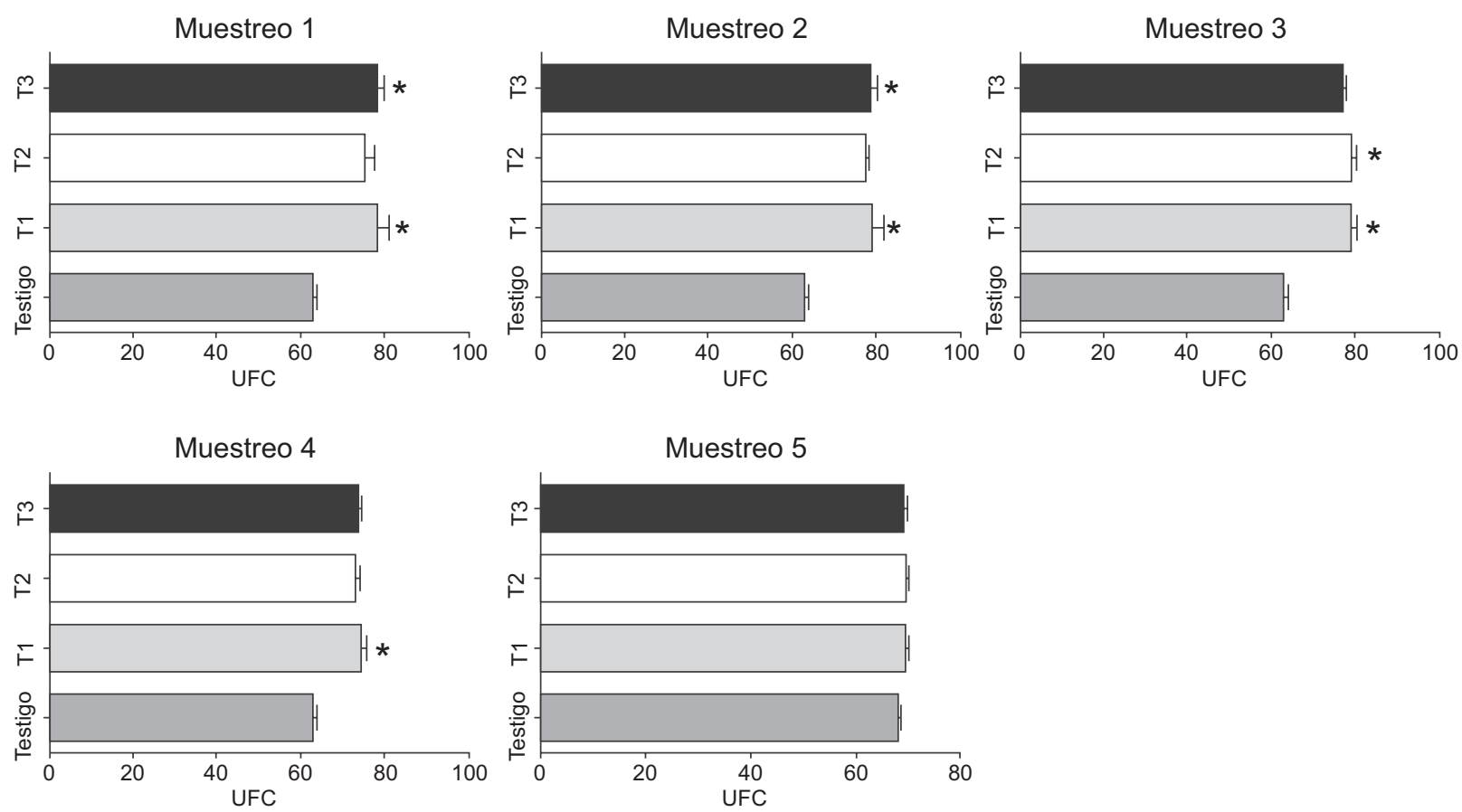

Fig. 4. Niveles de actividad bactericida del plasma en juveniles de cachama blanca (Piaractus brachypomus) expuestos a clorpirifós (CPF) por un periodo de 50 días. Los asteriscos describen diferencias significativas de los expuestos en cada tratamiento (T) vs. el grupo testigo: *unidades formadoras de colonia (UFC), $\mathrm{p}<0.05$.

\section{DISCUSIÓN}

Los estudios de toxicidad han permitido establecer criterios sólidos para la reevaluación del uso de agroquímicos en cultivos agrícolas y explotaciones pecuarias, tomando en cuenta el posible impacto de estas prácticas en el ambiente, así como en peces en producción. Los estudios de toxicidad de dosis letal media $\left(\mathrm{DL}_{50}\right)$ del CPF en animales terrestres y acuáticos han demostrado una alta toxicidad de este compuesto (Ali et al. 2008, Kavitha y Venkateswara 2008, Jin et al. 2015). La DL50 se ha descrito en animales como ratas $(118-250 \mathrm{mg} / \mathrm{kg})$, conejos $(1000 \mathrm{mg} / \mathrm{kg})$, cobayos $(504 \mathrm{mg} / \mathrm{kg})$, pollos de engorde $(40 \mathrm{mg} / \mathrm{kg})$ y caninos $(24 \mathrm{mg} / \mathrm{kg})$, entre otras especies.

En caninos también se han descrito valores de $\mathrm{DL}_{50}$ para los metabolitos del CPF, triclorpiridinol (7 mg/kg) y CPF oxón (12 mg/kg) (Tomlin 2000, Srebočan et al. 2003, Kammon et al. 2011). Estudios previos han descrito valores de $\mathrm{CL}_{50}$ a $96 \mathrm{~h}$ para peces como guppys (Poecilia reticulata) $(1790 \mu \mathrm{g} / \mathrm{L})$, trucha arco iris (Oncorhynchus mykiss) $(9 \mu \mathrm{g} / \mathrm{L})$, pez de branquias azules (Lepomis macrochirus) (10 $\mu \mathrm{g} / \mathrm{L}$ ), entre otras especies dulceacuícolas y marinas (USEPA 1986, Selvi et al. 2005) que se describen en el Cuadro I. Estos valores son mayores que los hallados para cachama blanca en el presente estudio, y cabe resaltar que algunos de dichos estudios se realizaron en animales jóvenes $(7,14$ y 28 días de vida), los cuales son más sensibles al efecto tóxico (Borthwic et al., 1985); aun así, los valores de CL50 son mayores a los descritos para la cachama blanca, lo cual evidencia la alta sensibilidad de esta especie nativa a este tipo de xenobióticos y su potencial uso como bioindicador de contaminación. Adicionalmente, algunos estudios han demostrado la variación en la sensibilidad al tóxico de una manera dependiente de la temperatura (Johnson y Finley 1980); no obstante, en los experimentos de este estudio, los parámetros de temperatura fueron constantes y considerados de confort para la especie.

Las alteraciones en el comportamiento (nado explosivo, cambios en movimientos de desplazamiento y estación, comportamiento de cardumen, reflejo de huida alterado, ubicación anormal en la columna de agua y agresividad) evidenciadas en los animales expuestos en este estudio, son similares a las reportadas en diversos estudios tras exposición a xenobióticos (Naranjo-Gómez et al. 2013, MarínMéndez et al. 2014) y concuerda con lo reportado por Halappa y Muniswamy (2009) para el CPF en carpa común. El nado explosivo y el aumento de los movimientos operculares durante los primeros 
CUADRO I. VALORES DE LETALIDAD (CL50) PARA CLORPIRIFÓS EN DIFERENTES ESPECIES DE PECES

\begin{tabular}{|c|c|c|}
\hline Especie & $\mathrm{CL}_{50}(\mu \mathrm{g} / \mathrm{L})$ & Referencia \\
\hline Piaractus brachypomus & 0.11 & Este estudio \\
\hline Menidia peninsulae & $0.7-3.0$ & \multirow{3}{*}{ Borthwic et al. 1985} \\
\hline Leuresthes tenuis & $1.1-3.1$ & \\
\hline Menidia sp. & $1.4-3.4$ & \\
\hline Fundulus similis & 4.1 & Schimmel et al. 1983 \\
\hline Lepomis macrochirus & $\begin{array}{l}5.1\left(13^{\circ} \mathrm{C}\right) \\
1.1\left(29^{\circ} \mathrm{C}\right)\end{array}$ & Johnson y Finley 1980 \\
\hline Pungitius sp. & 5.7 & Van et al. 1993 \\
\hline Oncorhynchus mykiss & 9 & \multirow{2}{*}{ USEPA 1986} \\
\hline Lepomis macrochirus & 10 & \\
\hline Gasterosteus aculeatus & 13.4 & Van et al. 1993 \\
\hline Oreochromis mossambicus & 25.97 & Rao et al. 2003 \\
\hline Oreochromis mossambicus & 82.14 & Aniladevi 2008 \\
\hline Salvelinus namaycush & 98 & USEPA 1986 \\
\hline Cyprinus carpio & 160 & Halappa et al. 2009 \\
\hline Ictalurus punctatus & 280 & Johnson y Finley 1980 \\
\hline Gambusia affinis & 290 & Rao et al. 2005, Kavitha y Venkateswara 2008 \\
\hline Gambusia affinis & 297 & Rao et al. 2005 \\
\hline Pimephales promelas & 331 & \multirow{2}{*}{ USEPA 1986} \\
\hline Carassius auratus & 806 & \\
\hline Channa punctatus & 800 & Ali et al. 2008 \\
\hline Oreochromis niloticus L. & 1570 & Gül 2005 \\
\hline Poecilia reticulata & 1790 & Selvi et al. 2005 \\
\hline
\end{tabular}

minutos de exposición al CPF, pueden obedecer a una respuesta de estrés de los animales frente a los cambios en el ambiente, evidenciada como un incremento de la actividad fisiológica (Neelima et al. 2016). Asimismo, estas alteraciones se pueden deber a la neurotoxicidad del CPF asociada a la inhibición de la acetilcolinesterasa (AChE) (Yang et al. 2008), así como a otras enzimas como la adenil ciclasa, la cual ha sido postulada como una de las vías de alteración nerviosa en salmónidos expuestos a CPF (Maryoung et al. 2014).

De otra parte, una mayor demanda de oxígeno obliga a patrones de boqueo y a búsqueda de concentraciones mayores de oxígeno en la superficie del agua durante el periodo de exposición (Katja et al. 2005), ya que la toma de aire superficial puede ayudar a minimizar el contacto con el medio tóxico (Patil y David 2008). Otros autores han descrito que las lesiones lamelares en branquias de peces expuestos a diferentes contaminantes del agua pueden disminuir la toma de oxígeno presente en el agua, generando así una mayor necesidad de captar oxígeno de la atmósfera (Couillard et al. 1988, Dalzell y Macfarlane 1999).
Este comportamiento se evidenció en el presente trabajo, a pesar de que las unidades experimentales contaron con aireación constante.

Las lesiones branquiales inducidas por exposición al tóxico también pueden desencadenar la letalidad evidenciada en el presente experimento. Debido a su amplia área de superficie epitelial en contacto con el agua circundante, el tejido branquial se convierte en órgano blanco y es el primero en reaccionar a los contaminantes del medio (Couillard et al. 1988, Dalzell y Macfarlane 1999); no obstante, las alteraciones inducidas en las branquias no sólo comprometen la respiración, sino también los mecanismos de osmorregulación y balance iónico, cuyo desequilibrio causa la muerte de los individuos (Couillard et al. 1988, Dalzell y Macfarlane 1999).

Por otra parte, estudios previos han demostrado que exposiciones breves a CPF incrementan la respuesta excitatoria reflejada en el nado explosivo del pez cebra (Danio rerio) (Eddins et al. 2010). Esto concuerda con los resultados evidenciados en el presente estudio, donde en las fases iniciales de exposición los peces presentaron movimientos 
rápidos acompañados de tremores y patrones erráticos de nado, alteraciones supeditadas a un incremento en la respuesta excitatoria producto de una mayor estimulación colinérgica de los receptores nicotínicos y muscarínicos (Eddins et al. 2010). En el pez cebra, la exposición a CPF causó una disminución significativa de los niveles basales de dopamina y serotonina y un incremento del intercambio de estos transmisores (Eddins et al. 2010), generando la respuesta excitatoria tras la exposición.

Adicionalmente, el CPF es un potente inhibidor de la $\mathrm{AChE}$, enzima responsable de la degradación hidrolítica de la acetilcolina, que es el neurotransmisor primario en los sistemas sensoriales y neuromusculares de la mayoría de las especies animales (Szabo et al. 1992, Behra et al. 2002, Yang et al. 2008). La inhibición de la $\mathrm{AChE}$ resulta en hiperestimulación de los receptores de acetilcolina, causando alteraciones que incluyen cambios del comportamiento, parálisis, convulsiones y daños a los procesos cognitivos y de control motor (Harder et al. 1998, Baxter et al. 1999). Aunado a lo anterior, se ha descrito que la acción inhibitoria del CPF sobre la AChE puede variar con el tamaño corporal del pez, siendo menor en animales de mayor tamaño (Chandrasekara y Pathiratne 2007), por lo cual es posible que en individuos de cachama blanca en estadios de desarrollo temprano el efecto pueda ser más marcado.

Los resultados muestran que la reducción del nado de los peces fue mayor a medida que aumentó el tiempo de exposición al tóxico y de manera dependiente de la concentración, lo cual es consistente con lo reportado por otros autores (Tilton et al. 2011). Algunos peces expuestos a las mayores concentraciones mostraron un patrón de bloqueo del nado, el cual ha sido descrito en peces expuestos a químicos ambientales y se refiere al cese de los movimientos natatorios y posterior caída al fondo del acuario, como una respuesta común para evitar depredadores (Treberg et al. 2002); sin embargo, también puede estar relacionado con alteraciones branquiales. Los cambios en el comportamiento de la cachama blanca evidenciados en el nado, son indicadores de la sensibilidad del pez a la toxicidad del CPF, por lo cual puede tomarse inicialmente como modelo bioindicador de la contaminación en fuentes hídricas a concentraciones ambientalmente esperadas.

Los cambios histopatológicos también se utilizan como bioindicadores en la vigilancia del medio ambiente y sus alteraciones. Los resultados histopatológicos observados en los tejidos de los alevinos de $P$. brachypomus en el presente estudio, indican que el CPF a concentración subletal causa alteraciones en branquias, hígado y riñón, órganos estrechamente relacionados con procesos metabólicos y de desintoxicación, así como funciones vitales como la respiración, osmorregulación y equilibrio ácido básico, entre otros (Xu et al. 2012). En este estudio se observaron además lesiones encefálicas tras la exposición a la concentración subletal definida.

Las lesiones branquiales evidenciadas en peces expuestos a CPF $(0.011 \mu \mathrm{g} / \mathrm{L})$, tales como hipertrofia del epitelio lamelar e hiperplasia moderada, concuerdan con lo reportado por otros autores respecto de la exposición a este compuesto (Gómez et al. 2002, Xing et al. 2012a, Devi y Mishra 2013). Estas alteraciones, pueden deberse a cambios adaptativos para evitar la difusión del tóxico al torrente sanguíneo (barrera mecánica), como se ha propuesto en otros estudios (Smart 1976, Nowak 1992, Ortiz et al. 2003, Ramírez-Duarte et al. 2008); sin embargo, dichas respuestas comprometerían la difusión de otras moléculas vitales, induciendo disturbios de la osmorregulación. Hallazgos como hiperplasia e hipertrofia del epitelio lamelar se han asociado con respuestas compensatorias al desprendimiento epitelial (Machado y Fanta 2003); no obstante, dichas lesiones también se han reportado en animales clínicamente sanos en el ambiente natural (Verjan-García 2002).

Cabe destacar que los sujetos experimentales de este estudio se encontraban en condiciones controladas de laboratorio y que tales alteraciones no fueron evidentes en el grupo testigo, por lo cual, en nuestra opinión, podrían estar vinculadas con la exposición crónica al CPF, descartándose además un efecto debido al $\mathrm{pH}$ del agua, el cual no presentó variaciones significativas entre los tratamientos.

En el hígado se evidenció degeneración vacuolar severa, pleomorfismo celular y ausencia de núcleos, alteraciones que podrían sugerir diferentes estadios de muerte celular, aunque la apoptosis no fue evidente. Ddichos cambios podrían atribuirse a un estado de adaptación metabólica a los compuestos plaguicidas (Mohamed 2009), dada la función del hígado en el catabolismo y transformación de las sustancias tóxicas (Camargo y Martínez 2007). En estudios previos se ha demostrado que la acumulación de lípidos a nivel hepático es un cambio inducido por el tóxico en casos de exposición a CPF (Nowak 1992, Ortiz et al. 2003, Ramírez-Duarte et al. 2008). Estos cambios se asocian con la generación de especies reactivas de oxígeno y a la depleción de enzimas antioxidantes, a su vez vinculadas con cambios estructurales hepáticos y con el incremento en los lípidos sanguíneos (Uzun y Kelender 2013). Olsvik et al. (2015) demostraron que la exposición a CPF induce acumulación intracelular 
de ácidos grasos de cadena larga y dipéptidos en los hepatocitos debido a cambios en la hidrólisis de lípidos complejos tales como triglicéridos, a partir de la evidencia de acumulación de monoacilgliceroles tales como 1-linoleoilglicerol y 1 -araquidonilglicerol. No obstante, en el presente estudio no se realizó tinción diferencial para lípidos en los tejidos estudiados.

De otra parte, se sabe que el riñón cumple funciones de destoxificación de compuestos circulantes en el torrente sanguíneo (Xing et al. 2012b), por lo cual se constituye en un órgano susceptible de lesión en las exposiciones a xenobióticos. Los hallazgos a nivel renal incluyeron depleción de leucocitos, degeneración hialina del epitelio tubular y pérdida de estructura y distribución del parénquima, así como incremento en la formación de centros de melanomacrófagos. Estas alteraciones renales han sido reportadas por varios autores como consecuencias de la exposición a CPF en otras especies de peces (Aliaa et al. 2011, Pal et al. 2012, Xing et al. 2012b, Wang et al. 2013).

Se ha demostrado que el encéfalo es un órgano susceptible ante la exposición a organofosforados (Saulsbury et al. 2009, Xing et al. 2012b, Mishra y Devi 2014). Las alteraciones encefálicas evidenciadas en el presente estudio (i.e., degeneración e hipertrofia neuronales, alteraciones nucleares) también han sido reportadas por otros autores en exposición subcrónica a OP (Lakshmaiah 2016). Estas lesiones pueden deberse a la inducción de estrés celular oxidativo, el cual altera la función mitocondrial y compromete la viabilidad celular, como se ha demostrado en varios estudios (Peng et al. 2015, Xing et al. 2012b, Xu et al. 2012). Dependiendo de la zona afectada, las lesiones neuronales pueden influir posteriormente en las actividades fisiológicas normales y también pueden asociarse con alteraciones comportamentales como aumento de los reflejos de huida y estrés (Xing et al. 2012b).

Las alteraciones histopatológicas encontradas en el presente estudio pueden estar asociadas a la exposición a $\mathrm{CPF}$, ya que no fueron evidentes en los peces del grupo testigo; sin embargo, a pesar de ser inducidas a concentraciones muy bajas del principio activo, en el ambiente natural, existen otras variables que pueden afectar la respuesta, incluyendo cambios en la densidad de los animales, depredación que genera biomagnificación, pluviosidad y cambios de pH asociados a la misma, así como fluctuación en la temperatura, todos ellos factores que incrementan el flujo y la concentración del tóxico al que están expuestos los peces (Varó et al. 2002, Jantunen et al. 2008).
Por otra parte, estudios previos han demostrado el efecto deletéreo de la exposición a organofosforados en general y al CPF en particular, sobre la respuesta inmunitaria primaria en peces (Oruc 2010, Marín-Méndez et al. 2014, Jin et al. 2015). El presente estudio demostró que la exposición a niveles subletales de CPF en cachama blanca indujo valores de actividad de explosión respiratoria menores en las primeras semanas; no obstante, dicha reducción no fue consistente en todas las concentraciones evaluadas, lo que dificulta establecer un comportamiento de esta variable en condiciones experimentales. Estos hallazgos concuerdan con lo descrito en otros trabajos (Marín-Méndez et al. 2014), en los cuales los cambios en la actividad oxidativa inducida por organofosforados sólo se presentaron a concentraciones bajas del tóxico y en las etapas tempranas de exposición.

Diversos trabajos han demostrado que la exposición a metales pesados (Naranjo-Gómez et al. 2014), herbicidas (Rondón-Barragán et al. 2012, 2014) y organofosforados tipo oxón (Oruç 2010, Jin et al. 2015), entre otros, inducen un incremento en la actividad oxidativa (estrés oxidativo), y que éste puede estar mediado por la alteración de los sistemas antioxidantes. Se ha postulado al sistema colinérgico como una de las posibles vías de inducción de estos cambios en la respuesta celular (Rondón-Barragán et al. 2010).

El presente estudio evidenció que la exposición a concentraciones subletales de CPF inducen disminución de la capacidad bactericida del plasma, lo cual ha sido demostrado en estudios previos en peces expuestos a xenobióticos (Sánchez-Dardon et al. 1997, Marín-Méndez et al. 2014, Naranjo-Gómez et al. 2014). Marín-Méndez et al. (2014) demostraron que la exposición subletal al organofosforado triclorfón (TCF) induce una reducción en la actividad bactericida del plasma a los 20 y 30 días de exposición, similar a lo encontrado en el presente estudio. Algunos autores han relacionado estos cambios con la capacidad bactericida, con disminución de péptidos/proteínas antibacterianas en el plasma (e.g., lisozima, complemento) o reducción en los niveles de anticuerpos específicos contra Aeromonas hydrophila (Siwicki et al. 1990, Li et al. 2013).

Por último, cabe resaltar que el CPF se ha descrito como un plaguicida útil para el control de larvas de mosquito y como insecticida general en acuicultura a dosis de 11-25 g/ha, 28-56 g/ha o 30-100 g/ha de CPF-metil (Eaton et al. 1985, WHO 1997). Tomando en cuenta los datos reportados en este trabajo, aunados a las características toxicológicas de estos 
compuestos, es necesario validar como ambientalmente seguros los valores reportados por entidades de control y respaldar dichos trabajos con estudios de toxicidad aguda y crónica subletal que garanticen el menor daño a poblaciones no blanco de la acción de los plaguicidas. Asimismo, Wan et al. (2000) describen la presencia de residuos de CPF en nueve de cada 10 bagres de canal (Ictalurus punctatus) de vida libre y en cultivo, así como en filetes ya procesados $(10.5 \%)$, por lo cual debe enfatizarse la importancia de estos aspectos en la salud ambiental y la salud pública.

\section{CONCLUSIONES}

El valor de la $\mathrm{CL}_{50}$ para el CPF en $P$. brachypo$m u s$, en las condiciones descritas en este estudio, es de $0.11 \mu \mathrm{g} / \mathrm{L}$ (IC $95 \%$ : 0.10-0.12; p < 0.05). Dicho valor es menor al reportado para otras especies dulceacuícolas y marinas y constituye uno de los escasos reportes de toxicidad en especies nativas. Asimismo, la alta sensibilidad de este carácido al CPF, así como las lesiones histopatológicas halladas en exposición crónica subletal, permiten la postulación de este pez como bioindicador de contaminación en fuentes hídricas y como modelo experimental para estudios de toxicidad subletal a otros compuestos. La exposición crónica subletal al CPF produce cambios en la explosión respiratoria y reduce la capacidad bactericida del suero; estas alteraciones pueden ser reversibles, pero pueden comprometer la capacidad de respuesta a los desafíos contra patógenos oportunistas o primarios en el medio.

\section{REFERENCIAS}

Ali D., Nagpure N.S., Kumar S., Kumar R. y Kushwaha B. (2008). Genotoxicity assessment of acute exposure of chlorpyrifos to freshwater fish Channa punctatus (Bloch) using micronucleus assay and alkaline singlecell gel electrophoresis. Chemosphere 71 (10), 18231831. DOI: 10.1016/j.chemosphere.2008.02.007

Aliaa I.M., Azza G.M. y Gehad E.M. (2011). Histological hazards of chlorpyrifos usage on gills and kidneys of tilapia nilotica and the role of vitamin E supplement. Egypt. Life Sci. 8 (4), 113-23.

Aniladevi K. (2008). Biochemical effects of the pesticide chlorpyrifos on the fish Oreochromis mossambicus (Peters). Tesis de Doctorado. Facultad de Biología Marina, Microbiología y Bioquímica, Cochin University of Science and Technology, Kerala, India, 251 pp.
Baxter M., Frick K., Price D., Breckler S., Markowska A. y Gorman L. (1999). Presynaptic markers of cholinergic function in the rat brain: relationship with age and cognitive status. Neuroscience 89 (3), 771-779. DOI: 10.1016/s0306-4522(98)00374-1

Behra M., Cousin X., Bertrand C., Vonesch J., Biellmann D., Chatonnet A. y Strähle T. (2002). Acetylcholinesterase is required for neuronal and muscular development in the zebrafish embryo. Nat. Neurosci. 5 (2), 111-118. DOI: 10.1038/nn788

Bisset-Lazcano J.A., Rodríguez M.M., San Martín J.L., Romero J.E. y Montoya R. (2009). Evaluación de la resistencia a insecticidas de una cepa de Aedes aegypti de El Salvador. Rev. Panam. Salud Pública. 26 (3), 229-234.

Borthwic P., Patrick J. y Middaugh J. (1985). Comparative acute sensitivities of early life stages of atherinid fishes to chlorpyrifos and thiobencarb. Arch. Environ. Con. Tox. 14, 465-473. DOI: 10.1007/BF01055533

Camargo M.M. y Martínez C.B. (2007). Histopathology of gills, kidney and liver of a neotropical fish caged in an urban stream. Neotro. Ichthyol. 5 (3), 327-336. DOI: $10.1590 / \mathrm{S} 1679-62252007000300013$

Campbell T. (2005) Performing a basic examination in fish. Veterinary medicine [en línea].

http://veterinarymedicine.dvm360.com/performing-basicexamination-fish 06/08/2017.

Chandrasekara L. y Pathiratne A. (2007). Body size-related differences in the inhibition of brain acetylcholinesterase activity in juvenile nile tilapia (Oreochromis niloticus) by chlorpyrifos and carbosulfan. Ecotox. Environ. Safe. 67 (1), 109-119. DOI: 10.1016/j.ecoenv.2006.04.002

Cohn J. y MacPhail R. (1996). Ethological and experimental approaches to behavior analysis: implications for ecotoxicology. Environ. Health Persp. 104 (Suppl 2), 299-305. DOI: $10.2307 / 3432649$

Couillard C.M., Berman R.A. y Panisset J.C. (1988). Histopathology of rainbow trout exposed to a bleached kraft pulp mill effluent. Arch. Environ. Con. Tox. 17 (3), 319-323. DOI: 10.1007/BF01055169

Dalzell D. y Macfarlane N. (1999). The toxicity of iron to brown trout and effects on gills: A comparison of two grades of iron sulphate. J. Fish Biol. 55 (2), 301-315. DOI: 10.1111/j.1095-8649.1999.tb00680.x

De A., Bose R., Kumar A. y Mozumdar S. (2014). Chapter 2: Worldwide pesticide use. En: Targeted delivery of pesticides using biodegradable polymeric nanoparticles. (A. De, R. Bose, A. Kumar y S. Mozumdar, Eds.). Springer, Nueva Delhi, India, pp. 5-6.

DOI: 10.1007/978-81-322-1689-6_2

Devi Y. y Mishra A. (2013). Histopathological alterations in gill and liver anatomy of fresh water, air breathing 
fish Channa punctatus after pesticide Hilban ${ }^{\circledR}$ (chlorpyrifos) treatment. Adv. Biores. 4 (2), 57- 62.

Drummond R. y Russom C. (1990). Behavioral toxicity syndromes: A promising tool for assessing toxicity mechanisms in juvenile fathead minnows. Environ. Toxicol. Chem. 9 (1), 37-46.

DOI: $10.1002 /$ etc.5620090106

Eaton J., Arthur J., Hermanntz R., Kiefer R., Mueller L., Anderson R., Erickson R., Nordling B., Rogers J. y Pritchard H. (1985). Biological effects of continuous and intermittent dosing of outdoor experimental streams with chlorpyrifos. Memorias del VIII Symposium of the ASTM International Aquatic Toxicology and Hazard Assessment, Filadelfia, EUA. 15 al 17 de abril, pp. 85-118. DOI: 10.1520/STP33568S

Eddins D., Cerutti D., Williams P., Linney E. y Levin E.D. (2010). Zebrafish provide a sensitive model of persisting neurobehavioral effects of developmental chlorpyrifos exposure: comparison with nicotine and pilocarpine effects and relationship to dopamine deficits. Neurotoxicol. Teratol. 32 (1), 99-108.

DOI: $10.1016 /$ j.ntt.2009.02.005

FAOSTAT (2015). FAO statistical pocketbook 2015. World food and agriculture, Reporte. Statistics Division-Food and Agriculture Organization of the United Nations, Roma, Italia, 236 pp.

Floyd R. (1999). Clinical examination of fish in private collections. Vet. Clin. North. Am. Exot. Anim. Pract. 2 (2), 247-264. DOI: 10.1016/S1094-9194(17)30124-X

García-Vidal L., Martínez-Aguirre M.R. y Bielza P. (2014). Línea base de susceptibilidad y selección de poblaciones resistentes de Tuta absoluta (Meyrick) (Lepidoptera: Gelechiidae). Memorias de Congreso. III Workshop en Investigación AgroalimentariaWiA3.14. Cartagena, Colombia, 12 al 13 de mayo, pp. 100-274.

Gómez L., Durán E., Gázquez A., Martínez S., Masot J. y Roncero V. (2002). Lesions induced by 2,4-d and chlorpyrifos in tench (Tinca L.): implication in toxicity studies. J. Environ. Sci. Health. B. 37 (1), 43-51. DOI: $10.1081 /$ PFC-120002896

Gül A. (2005). Investigation of acute toxicity of chlorpyrifos-methyl on Nile tilapia (Oreochromis niloticus L.) larvae. Chemosphere 59 (2), 163-166. DOI: 10.1016/j.chemosphere.2004.10.065

Halappa R., y Muniswamy D. (2009). Behavioural responses of the freshwater fish, Cyprinus carpio (Linnaeus) following sublethal exposure to chlorpyrifos. Turkish J. Fish Aquat. Sci. 9 (2), 233-238.

DOI: $10.4194 /$ trjfas.2009.0218

Hamilton A., Russo R. y Thurston R. (1977). Trimmed Spearman-Karber method for estimating median lethal concentrations in toxicity bioassays. Environ. Sci.
Technol. 11 (7), 714-719. DOI: 10.1021/es60130a004

Harder J., Baker J. y Ridley R. (1998). The role of the central cholinergic projections in cognition: Implications of the effects of scopolamine on discrimination learn by monkeys. Brain Res. Bull. 45 (3), 319-326. DOI: 10.1016/S0361-9230(97)00381-X

Jantunen A.P., Tuikka A., Akkanen J. y Kukkonen J.V. (2008). Bioaccumulation of atrazine and chlorpyrifos to Lumbriculus variegatus from lake sediments. Ecotoxicol. Environ. Saf. 71 (3), 860-868.

DOI: $10.1016 /$ j.ecoenv.2008.01.025

Jin Y., Liu Z., Peng T. y Fu Z. (2015). The toxicity of chlorpyrifos on the early life stage of zebrafish: A survey on the endpoints at development, locomotor behavior, oxidative stress and immunotoxicity. Fish Shellfish Immunol. 43 (2), 405-414.

DOI: $10.1016 /$ j.fsi.2015.01.010

Johnson W. y Finley M. (1980). Handbook of acute toxicity of chemicals to fish and aquatic invertebrates: Summaries of toxicity tests conducted at Columbia National Fisheries Research Laboratory [en línea]. https://pubs. usgs.gov/unnumbered/37236/report.pdf 06/02/17.

Kammon A., Brar R., Sodhi S., Banga H., Singh J. y Nagra N. (2011). Chlorpyrifos chronic toxicity in broilers and effect of vitamin C. Open Vet. J. 1 (1), 21-27.

Katja S., Georg S., Stephan P. y Christian S. (2005). Impact of PCB mixture (Aroclor 1254) and TBT and a mixture of both on swimming behaviour, body growth and enzymatic biotransformation activities (GST) of young carp (Cyprinus carpio). Aquat. Toxicol. 71 (1), 49-59. DOI: $10.1016 / j$.aquatox.2004.10.012

Kavitha P. y Venkateswara R. (2008). Toxic effect of chlorpyrifos on antioxidant enzymes and target enzyme acetylcholinesterase interaction in mosquito fish, Gambusia affinis. Environ Toxicol Phar. 26 (2), 192-198. DOI: 10.1016/j.etap.2008.03.010

Khalil F., Kang I.J., Undap S., Tasmin R., Qiu X., Shimasaki Y. y Oshima Y. (2013). Alterations in social behavior of Japanese medaka (Oryzias latipes) in response to sublethal chlorpyrifos exposure. Chemosphere 92 (1), 125-130. DOI: 10.1016/j.chemosphere.2013.02.042

Kimbrough R. y Litke D. (1996). Pesticides in steams draining agricultural and urban areas in Colorado. Environ. Sci. Technol. 30 (3), 908-916.

DOI: $10.1021 / \mathrm{es} 950353 \mathrm{~b}$

Lakshmaiah G. (2016). A study on the effect of organophosphorus insecticide phorate on brain histopathology of the common carp Cyprinus carpio. Int. J. Fauna Biol. Stud. 3 (4), 39-43.

Li X., Liu L., Zhang Y., Fang Q., Li Y. y Li Y. (2013). Toxic effects of chlorpyrifos on lysozyme activities, the contents of complement $\mathrm{C} 3$ and $\operatorname{IgM}$, and $\operatorname{IgM}$ and complement $\mathrm{C} 3$ expressions in common carp (Cyprinus 
carpio L.). Chemosphere 93 (2), 428-433.

DOI: 10.1016/j.chemosphere.2013.05.023

Luna L.G. (1968). Manual of histologic staining methods of the Armed Forces Institute of Pathology. 3ra ed. Blakiston Division McGraw-Hill, Nueva York, EUA, $258 \mathrm{pp}$.

Machado M. y Fanta E. (2003). Effects of the organophosphorous methyl parathion on the branchial epithelium of a freshwater fish Metynnis eoosevelti. Brazi. Arch. Biol. Technol. 46 (3), 361-372.

DOI: $10.1590 / \mathrm{S} 1516-89132003000300008$

Marín-Méndez G.A., Chacón-Novoa R.A., CéspedesRubio A.E. y Rondón-Barragán I.S. (2014). Efectos toxicológicos generados por la exposición a triclorfón en un modelo inducido experimentalmente en cachama blanca (Piaractus brachypomus). CES Med. Vet. Zootec. 9 (2), 190-202.

Maryoung L., Lavado R. y Schlenk D. (2014). Impacts of hypersaline acclimation on the acute toxicity of the organophosphate chlorpyrifos to salmonids. Aquatic Toxicol. 152, 284-290. DOI: 10.1016/j.aquatox.2014.04.017

Mehler W., Schuler L. y Lydy M. (2008). Examining the joint toxicity of chlorpyrifos and atrazine in the aquatic species: Lepomis macrochirus, Pimephales promelas, and Chironomus tetans. Environ. Pollut. 152 (1), 217224. DOI: 10.1016/j.envpol.2007.04.028

Mishra A. y Devi Y. (2014). Histopathological alterations in the brain (optic tectum) of the freshwater teleost Channa punctatus in response to acute and subchronic exposure to the pesticide chlorpyrifos. Acta Histochem. 116 (1), 176-181. DOI: 10.1016/j.acthis.2013.07.001

Mohamed F.A. (2009). Histopathological studies on Tilapia zillii and Solea vulgaris from lake Qarun, Egypt. World J. Fish and Mari. Sci. 1 (1), 29-39.

Mohanty B.R. y Sahoo P.K. (2010). Immune responses and expression profiles of some immune-related genes in Indian major carp, Labeo rohita to Edwardsiella tarda infection. Fish Shellfish Immunol. 28 (4), 613-21. DOI: 10.1016/j.fsi.2009.12.025

Naddy R. y Klaine S. (2001). Effect of pulse frequency and interval on the toxicity of chlorpyrifos to Daphnia magna. Chemosphere 45 (4-5), 497-506.

DOI: $10.1016 / \mathrm{S} 0045-6535(01) 00019-4$

Naranjo-Gómez J.S., Chacón-Novoa R., Zambrano-Cardona F., Uribe-García F., Ramírez K., Vargas-Morales J.A. y Rondón-Barragán I.S. (2014). Efectos inmunotoxicológicos e histopatológicos de la exposición a concentraciones subletales de cloruro de mercurio $\left(\mathrm{HgCl}_{2}\right)$ en cachama blanca (Piaractus brachypomus). CES Med. Vet. Zootec. 9 (1), 26-42.

Nowak B. (1992). Histological changes in gills induced by residues of endosulfan. Aquat. Toxicol. 23 (1), 65-84. DOI: $10.1016 / 0166-445 X(92) 90012-C$
OECD (1992). Essai $n^{\circ}$ 203: Poisson, essai de toxicité aiguë. Lignes directrices de l'OCDE pour les essais de produits chimiques, section 2. Organization for Economic Co-operation and Development. Manual. Paris, Francia, 9 pp.

DOI: $10.1787 / 9789264069978-f r$

Olsvik P.A., Berntssen M.H.G. y Søfteland L. (2015). Modifying effects of vitamin E on chlorpyrifos toxicity in Atlantic salmon. Plos One 10 (3). 1-21.

DOI: 10.1371/journal.pone.0119250

Ortiz J., de Canales M. y Sarasquete C. (2003). Histopathological changes induced by lindane $(\gamma-\mathrm{HCH})$ in various organs of fishes. Sci. Mar. 67 (1), 53-61.

Oruç E.Ö. (2010). Oxidative stress, steroid hormone concentrations and acetylcholinesterase activity in Oreochromis niloticus exposed to chlorpyrifos. Pestic. Biochem. Phys. 96 (3), 160-166.

DOI: 10.1016/j.pestbp.2009.11.005

Páez-Jerez P.G., Carrizo B.N., Musse R., Varela E., Armiñana A., Milla F., Vera M.T. y de la Vega M.H. (2015). Datos de nivel básico de cuatro insecticidas con diferentes mecanismos de acción para Anastrepha fraterculus y Ceratitis capitata (Diptera: Tephritidae). Rev. Agron. Noroeste Argent. 35 (1), 37-43.

Pal S., Kokushi E., Koyama J., Uno S. y Ghosh A.R. (2012). Histopathological alterations in gill, liver and kidney of common carp exposed to chlorpyrifos. J. Environ. Sci. Heal. B 47 (3), 180-195.

DOI: $10.1080 / 03601234.2012 .632285$

Patil V. y David M. (2008). Behaviour and respiratory dysfunction as an index of malathion toxicity in the freshwater fish, Labeo rohita (Hamilton). Turk. J. Fish. Aquat. Sci. 8, 233-237.

Peng H.F., Bao X.D., Zhang Y., Huang L. y Huang H.Q. (2015). Identification of differentially expressed proteins of brain tissue in response to methamidophos in flounder (Paralichthys olivaceus). Fish Shellfish Immunol. 44 (2), 555-565.

DOI: $10.1016 /$ j.fsi.2015.03.028

Pimentel D. (1995). Amounts of pesticides reaching target pests: Environmental impacts and ethics. J. Agric. Environ. Ethics 8 (1), 17-29. DOI: 10.1007/BF02286399

Rainger G. y Rowley A. (1993). Antibacterial activity in the serum and mucus of rainbow trout, Oncorhynchus mykiss, following immunization with Aeromonas salmonicida. Fish Shellfish Immunol. 3 (6), 475-482. DOI: $10.1006 /$ fsim.1993.1046

Ramírez-Duarte W.F., Rondón-Barragán I.S. y EslavaMocha P.R. (2008). Acute toxicity and histopathological alterations of Roundup ${ }^{\circledR}$ herbicide on cachama blanca (Piaractus brachypomus). Pesq. Vet. Bras. 28 (11), 547-554.

DOI: 10.1590/S0100-736X2008001100002 
Rao J., Ghousia B., Pallela R., Usman P. y Rao N. (2005). Changes in behavior and brain acetylcholinesterase activity in mosquito fish, Gambusia affinis in response to the sub-lethal exposure to chlorpyrifos. Int. J. Environ. Res. Public Health 2 (3), 478-483.

Rondón-Barragán I.S., Marín-Méndez G., Chacón-Novoa R., Naranjo-Suárez L. y Eslava P.R. (2014). Efectos del Roundup ${ }^{\circledR}$ y Cosmoflux ${ }^{\circledR} 411 \mathrm{~F}$ sobre la respuesta inmune frente al desafío con Aeromonas hydrophila en cachama blanca (Piaractus brachypomus). Rev. Orinoquía 18 (2), 38-51.

Sánchez-Dardon J., Voccia I., Hontela A., Anderson P., Brousseau P., Blakely B., Boermans H. y Fournier M. (1997). Immunotoxicity of cadmium, zinc and mercury after in vivo exposure, alone or in mixture in rainbow trout (Oncorhynchus mykiss). Dev. Comp. Immunol. $21(2), 133$.

Saulsbury M.D., Heyliger S.O., Wang K. y Johnson D.J. (2009). Chlorpyrifos induces oxidative stress in oligodendrocyte progenitor cells. Toxicology 259 (1-2), 1-9. DOI: 10.1016/j.tox.2008.12.026

Schimmel S., Garnas R., Patrck J. y Moore J. (1983). Acute toxicity bioconcentration and persistence of AC 222, 705 , benthiocarb, chlorpyrifos fenvalerate, methyl parathion, and permethrin in the estuarine environment. J. Agr. Food Chem. 31 (1), 104-113.

DOI: 10.1021/jf00115a027

Selvi M., Sarikaya R., Erkoc F., y Kocak O. (2005). Investigation of acute toxicity of chlorpyrifos methyl on Poecilia reticulata. Chemosphere 60 (1), 93-96. DOI: 10.1016/j.chemosphere.2004.11.093

Sharbidre A., Metkari V. y Patode P. (2011). Effect of methyl parathion and chlorpyrifos on certain biomarkers in various tissues of guppy fish, Poecilia reticulata. Pestic. Biochem. Phys. 101 (2), 132-141.

DOI: 10.1016/j.pestbp.2011.09.002

Siwicki A.K., Cossarini-Dunier M., Studnicka M. y Demael A. (1990). In vivo effect of the organophosphorus insecticide trichlorphon on immune response of carp (Cyprinus carpio) II. Effect of high doses of trichlorphon on nonspecific immune response. Ecotoxicol. Environ. Saf. 19 (1), 99-105.

DOI: 10.1016/0147-6513(90)90084-I

Smart G. (1976). The effect of ammonia exposure on gill structure of the rainbow trout (Salmo gairdneri). Fish Biol. 8 (6), 471-475.

DOI: $10.1111 / \mathrm{j} .1095-8649.1976 . t b 03990 . x$

Srebočan E., Hrlec G., Grabarević Ž., Pompe-Gotal J. y Sabočanec R. (2003). Poisoning with acetylcholinesterase inhibitors in dogs: two cases reports. Vet. Med. Czech 48 (6), 175-176.

Szabo A., Nemcsok J., Asztalos B., Rakonczay Z., Kasa P. y Hieu L.H. (1992). The effect of pesticides on carp (Cyprinus carpio L). Acetylcholinesterase and its biochemical characterization. Ecotox. Environ. Safe. 23 (1), 39-45. DOI: 10.1016/0147-6513(92)90020-4

Tilton F., Bammler T., y Gallagher E. (2011). Swimming impairment and acetylcholinesterase inhibition in zebrafish exposed to copper or chlorpyrifos separately, or as mixtures. Comp. Biochem. Physiol. C. Toxicol. Pharmacol. 153 (1), 9-16.

DOI: $10.1016 /$ j.cbpc.2010.07.008

Tomlin C. (2000). The pesticide manual: A world compendium. 12a ed. British Crop Protection Council, Farnham, Surrey, Inglaterra, $1250 \mathrm{pp}$.

Treberg J., Wilson C., Richards R., Ewart K. y Driedzic W. (2002). The freeze-avoidance response of smelt Osmerus mordax: Initiation and subsequent suppression of glycerol, trimethylamine oxide and urea accumulation. J. Exp. Biol. 205, 1419-1427.

USEPA (1986). Ambient aquatic life water quality criteria for chlorpyrifos. United States Environmental Protection Agency, Washington, D.C., EUA, 71 pp.

Uzun F.G. y Kalender Y. (2013). Chlorpyrifos induced hepatotoxic and hematologic changes in rats: the role of quercetin and catechin. Food Chem. Toxicol. 55, 549-556.

DOI: $10.1016 /$ j.fct.2013.01.056

Van W., Leeuwangh P., Lucassen W., Romijn K., Ronday R., van der Velde R. y Willigenburg W. (1993). Acute toxicity of chlorpyrifos to fish, a newt, and aquatic invertebrates. Bull. Environ. Contam. Toxicol. 51, 716-723.

Varó I., Serrano R., Pitarch E., Amat F., López F.J. y Navarro J.C. (2002). Bioaccumulation of chlorpyrifos through an experimental food chain: Study of protein HSP70 as biomarker of sublethal stress in fish. Arch. Environ. Contam. Toxicol. 42 (2), 229-235. DOI: $10.1007 / \mathrm{s} 00244-001-0013-6$

Verjan-García N. (2002). Sistematización y caracterización de las enfermedades de la cachama blanca (Piaractus brachypomus) en algunas regiones de los Llanos Orientales y fisiopatología de la enfermedad septicémica. Tesis de Maestría. Facultad de Medicina Veterinaria y Zootecnia, Universidad Nacional de Colombia, Bogotá, Colombia, 185 pp.

Wan P., Santerre C. y Deardorff D. (2000). Chlorpyrifos in catfish (Ictalurus punctatus) Tissue. Bull. Environ. Contam. Toxicol. 65 (1), 84-90. DOI: $10.1007 / \mathrm{s} 001280000098$

Wang X., Xing H., Jiang Y., Wu H., Sun G., Xu Q. y Xu S. (2013). Accumulation, histopathological effects and response of biochemical markers in the spleens and head kidneys of common carp exposed to atrazine and chlorpyrifos. Food Chem. Toxicol. 62, 148-158. DOI: $10.1016 /$ j.fct.2013.08.044 
WHO (1997). Chemical methods for the control of vectors and pests of public health importance. World Health Organization, Ginebra, Suiza, $129 \mathrm{pp}$.

WHO (2004). The WHO recommended classification of pesticides by hazard and guidelines to classification: 2004. World Health Organization, Ginebra, Suiza, $56 \mathrm{pp}$.

Xing H., Li S., Wang Z., Gao X., Xu S. y Wang X. (2012a). Oxidative stress response and histopathological changes due to atrazine and chlorpyrifos exposure in common carp. Pestic. Biochem. Phys. 103 (1), 74-80. DOI: 10.1016/j.pestbp.2012.03.007

Xing H., Li S., Wang Z., Gao X., Xu S. y Wang X. (2012b). Histopathological changes and antioxidant response in brain and kidney of common carp exposed to atrazine and chlorpyrifos. Chemosphere 88 (4), 377-383.

DOI: 10.1016/j.chemosphere.2012.02.049
Xu W., Liu W., Shao X., Jiang G. y Li X. (2012). Effect of trichlorfon on hepatic lipid accumulation in crucian carp Carassius auratus gibelio. J. Aquat. Anim. Health 24 (3), 185-194. DOI: 10.1080/08997659.2012.675937

Yang D., Howard A., Bruun D., Ajua-Alemanj M., Pickart, C. y Lein P.J. (2008). Chlorpyrifos and chlorpyrifosoxon inhibit axonal growth by interfering with the morphogenic activity of acetylcholinesterase. Toxicol. Appl. Pharm. 228 (1), 32-41.

DOI: 10.1016/j.taap.2007.11.005

Yanong R.P.E. (2003). Necropsy techniques for fish. J. Exot. Pet Med. 13 (2), 89-105.

DOI: $10.1053 /$ saep.2003.127885 